\title{
Grupos de comunicación en España: madurez y profundas transformaciones en un final de ciclo
}

\section{José Vicente García-Santamaría ${ }^{1}$ María José Pérez-Serrano²}

Recibido: 06/07/2018

Aprobado por pares: 11/12/2018
Enviado a pares: 21/09/2018

Aceptado: 15/01/2019

DOI: $10.5294 /$ pacla.2020.23.4.5

Para citar este artículo / to reference this article / para citar este artigo García-Santamaría, J. V. y Pérez-Serrano, M. J. (2020). Grupos de comunicación en España: madurez y profundas transformaciones en un final de ciclo. Palabra Clave, 23(4), e2345. https://doi.org/10.5294/pacla.2020.23.4.5

\section{Resumen}

Los grupos de comunicación españoles han sufrido importantes transformaciones en los últimos cuarenta años. Las principales razones obedecen, sobre todo, a los fallidos intentos de integración vertical desarrollados en la década de los noventa, el escaso expertise en la industria televisiva y audiovisual, así como el elevado endeudamiento bancario. Una situación que se vio, además, agravada por la grave crisis económica sufrida en España entre 2007 y 2016, y, como es natural, por la adaptación al nuevo marco digital. En cualquier caso, parece claro que, al igual que está sucediendo en otros países desarrollados, estos grupos se encuentran en un momento de "madurez", que puede llegar a comportar importantes transformaciones en el panorama mediático español. Este análisis apunta, a modo de prospectiva, la imposibilidad de que los tradicionales grupos de comunicación puedan seguir manteniendo en el futuro el mismo statu quo de estas últimas déca-

\footnotetext{
https://orcid.org/0000-0003-4659-3975. Universidad Carlos III de Madrid, España. jvgsanta@hum.uc3m.es https://orcid.org/0000-0002-2190-7619. Universidad Complutense de Madrid, España.

mariajoseperezserrano@pdi.ucm.es
} 
das. Para ello, desarrolla el análisis bajo un prisma diacrónico y plantea una visión de futuro que, probablemente, se manifieste en dos hechos relevantes: la casi totalidad de los viejos grupos anclados en la prensa tenderán a desaparecer, fragmentarse o integrarse en nuevas plataformas de medios; $y$ el resto de grupos, cuyos "oficios de base" no provienen del mundo periodístico, se enfrentarán a una fuerte disputa por los contenidos, y competirán también con nuevos players, como las empresas de telefonía, las grandes empresas de internet y las plataformas de video on demand (VOD).

\section{Palabras clave (Fuente: tesauro de la Unesco)}

Economía de la comunicación; industria de telecomunicaciones; periodismo; contenidos; teoría de la información 


\section{Media Conglomerates in Spain: Maturity and Profound Transformations at the End of a Cycle}

\section{Abstract}

Spanish media conglomerates have undergone dramatic transformations in the last 40 years. The main reasons are the unsuccessful attempts at vertical integration in the 1990s, the scarce expertise in the television and audiovisual industry, and the high bank debt. This situation was also aggravated by the severe economic crisis Spain suffered between 2007-2016 and adaptation to the new digital framework. In any case, as is happening in other developed countries, these conglomerates are clearly "maturing," which may result in remarkable changes in the Spanish media landscape. This analysis prospectively points to the impossibility that traditional media conglomerates can continue to maintain the same status quo of the last decades. Through a diachronic prism, it proposes a vision of the future that is probably apparent in two relevant facts: almost all of the old conglomerates anchored in the press will tend to disappear, fragment, or merge into new media platforms and the rest, whose "grassroots trades" are not journalismrelated, will face an intense dispute over contents and compete with new players, such as telephone companies, large internet service providers, and VOD platforms.

\section{Keywords (Source: Unesco Thesaurus)}

Economy of communications; telecommunications industry; journalism; content; information theory 


\section{Grupos de comunicação na Espanha: maturidade e profundas transformações em um final de ciclo}

\section{Resumo}

Os grupos de comunicação espanhóis vêm sofrendo importantes transformações nos últimos quarenta anos. As principais razões obedecem, principalmente, às tentativas fracassadas de integração vertical desenvolvidas na década dos 1990, à escassa especialização na indústria televisiva e audiovisual, bem como ao elevado endividamento bancário. Uma situação que se viu, além disso, agravada pela grave crise econômica sofrida na Espanha entre 2007 e 2016, e, como é natural, pela adaptação ao novo contexto digital. Em qualquer caso, parece claro que, assim como o que está acontecendo em outros países desenvolvidos, esses grupos se encontram em um momento de "maturidade", que pode chegar a comportar importantes transformações no panorama midiático espanhol. Esta análise aponta, como prospectiva, a impossibilidade de que os tradicionais grupos de comunicação possam continuar mantendo no futuro do mesmo statu quo destas últimas décadas. Para isso, desenvolve a análise sob um prisma diacrônico e propõe uma visão de futuro que, provavelmente, é manifestada em dois fatos relevantes: a quase totalidade dos velhos grupos ancorados na imprensa tenderá a desaparecer, fragmentar-se ou integrar-se em novas plataformas de meios; o restante de grupos, cujos "ofícios de base" não provêm do mundo jornalístico, enfrentará uma forte disputa pelos conteúdos e competirá também com novos players, como as empresas de telefonia, as grandes empresas de internet e das plataformas de video on demand (VOD).

\section{Palavras-chave (Fonte: tesauro da Unesco)}

Economia da comunicação; indústria de telecomunicações; jornalismo; conteúdo; teoria da informação 


\section{Introducción y estado de la cuestión}

El sistema de medios español ha sido objeto de estudio a lo largo de las últimas décadas, pero, quizá, siguiendo la tesis de Martínez y Saperas (2011, 2016), en algunas ocasiones, las investigaciones se han focalizado más en el ámbito periodístico. De ahí que el periodo que media entre 1980 y 2017 merezca un claro interés investigador.

En esta línea histórico-estructural, aunque los más importantes grupos de comunicación españoles empiezan a conformarse tras la muerte de Francisco Franco y la llegada de la democracia, puede señalarse con propiedad que hasta la creación de las televisiones privadas (Ley 10/1988, de 3 de mayo de 1988) no puede hablarse de "grupos multimedia". Será, por tanto, a finales de la década de los ochenta y a principios de la década de los noventa cuando irrumpan en España, con capital nacional o extranjero (caso de Mediaset Italia y Bertelsmann), la casi totalidad de conglomerados mediáticos que acabarán teniendo una decisiva presencia en el panorama mediático español: Prisa, Grupo Correo, Planeta, Zeta, Godó y Telecinco.

Durante estos años, la información sobre la situación de los media, y sobre los grupos que los sustentaban, encontraron un fértil campo de abono en los imprescindibles anuarios de la Fundación para el Desarrollo de la Función Social de las Comunicaciones (Fundesco), Fundación Telefónica y el Grupo Zeta, mientras que los anuarios de la Asociación de la Prensa de Madrid (APM) o de la Asociación de Editores de Diarios Españoles (AEDE) facilitaban una información no integrada de los diferentes sectores de actividad y se centraban en buena parte en los fenómenos periodísticos (García, 2016b). En cualquier caso, y como indicaba Díaz Nosty (2001), con estos informes anuales de la comunicación de 1989 a 1996, editados primero por Fundación Telefónica y después por el Grupo Zeta, se llevó a cabo una crónica regular del sistema español de medios, algo que solo se repetiría coyunturalmente en 2006 con otro estudio patrocinado por Fundación Telefónica.

Ya en el siglo XXI solo es posible encontrar algunas publicaciones digitales (caso de Digimedios) que ofrecen un tratamiento menos porme- 
norizado y de carácter más coyuntural o simplemente más genérico (Asociación de Medios de Información [AMI]), centrados en un único sector (Kantar Media/Barlovento Comunicación) o, incluso, de carácter regional (Informe de la comunicació a Catalunya). Además, claro está, de la información ofrecida en sus memorias y balances anuales por todos aquellos grupos de comunicación que cotizan en la Bolsa española (Mediaset España, Atresmedia, Prisa, Vocento y Telefónica), y que contrastan con la opacidad de los no cotizados (Mediapro, Planeta, Godó, Grupo Zeta, y grupos de prensa regional).

Los media españoles parten, igualmente, de una situación peculiar y de difícil asimilación en la Unión Europea (UE). Hasta la muerte de Franco, en 1975, y la celebración de las primeras elecciones democráticas de 1976, estos medios estuvieron sometidos al control de la censura, y existían, además, los llamados "Medios de Comunicación Social del Estado, un conglomerado de 33 diarios, agencias de prensa, cadenas de radio y una televisión pública, que desaparecerían tras la aprobación de la Ley 11/1982, de 13 de abril de 1982, que posibilitó su enajenación (Fernández y Santana, 2000). Fue a partir de ese momento cuando comenzaron a surgir nuevas iniciativas empresariales en el campo de la prensa y las revistas, y también en el ámbito radiofónico (Álvarez, 1989), mientras que las cadenas de televisión privada no aparecerían — como hemos comentado — hasta la promulgación de la Ley 10/1988, de 3 de mayo de 1988.

Pero, poco a poco, como indicaba Jones (1996), España se fue adaptando progresivamente a su entorno europeo y, en poco tiempo, su sistema comunicativo apenas difería del imperante en la UE. En 1986, se produjo la integración de España en la UE, y se liberalizó la legislación para permitir la entrada de capital extranjero en todos los sectores económicos, con la consiguiente toma de posición de grandes corporaciones multinacionales en el mercado español.

En esos primeros años de democracia, a los tres grupos privados que habían operado desde el final de la Guerra Civil (Prensa Española, Godó y Editorial Católica) se le sumaron aquellos proyectos nacidos en la nueva etapa. Por tanto, los nuevos grupos de comunicación que irían conformán- 
dose se beneficiarían de un marco competencial muy débil y muy focalizado en la prensa; sector que manejaba entonces, y según datos de Fundesco (1989), más de EUR 4400 millones. Pero la principal debilidad de las empresas periodísticas era que sus directivos estaban poco avezados en proyectos radiofónicos y televisivos, y las empresas que los empleaban no dudaban en recurrir al "apalancamiento financiero" para financiar sus inversiones en diferentes sectores.

A partir de entonces también se pondría en práctica lo que los responsables de Fundesco pasarían a denominar "oligopolio mutante", afortunada expresión que describía cómo, de manera sucesiva, tres o, a lo sumo, cuatro grandes grupos iban turnándose en el dominio de los media españoles. Así, y como se mostrará a lo largo de este artículo, a los grupos dominantes en la dictadura le sucedieron ya en la década de los ochenta Prisa, Correo y Grupo Zeta; en la década de los noventa, Prisa, Telefónica y Vocento (sucesora del Correo); a comienzos del siglo XXI, Prisa, Planeta y Vocento; y, actualmente, Telefónica, Mediapro y Planeta.

\section{Objetivos, hipótesis y metodología}

Los criterios para valorar el planteamiento de un problema de investigación, según Kerlinger y Lee (2002), son los siguientes: debe expresarse como una relación entre dos o más variables, tiene que ser redactado en forma de pregunta y debe implicar la posibilidad de ser sometido a una prueba empírica.

Siguiendo con esta línea y sin llegar, quizá, a la exhaustividad antepuesta, este trabajo pretende, por un lado, efectuar un sucinto balance sobre los grupos mediáticos en atención a su historia a partir de la llegada de la democracia y analizar cómo, tras la grave crisis económica de 2007 a 2016, han evolucionado estas empresas y sus medios. Y, por otro lado, llevar a cabo una labor de prospectiva que proyecte escenarios de futuro según el binomio "ganadores y perdedores", así como ver aquellos grupos que siguen las tendencias de la comunicación mundial y los que han quedado relegados a un ámbito doméstico y más periodístico. Estos objetivos parten de la necesidad propia de historiar (con la dificultad cronológica que esto supone) algunos momentos clave en la gestión financiera de los grupos de comunicación en España. 
Para ello, se fija una hipótesis que queda formulada así: la situación cambiante de los grupos de comunicación españoles y los factores endógenos y exógenos que condicionan su estrategia y evolución hacen que la posición relativa en el mercado de cada uno de estos sujetos mercantiles haya variado a lo largo de los años y, en especial, después de la última crisis económica. Esta proposición conjetural se completa con una visión de futuro arriesgada, pero fundamentada en datos, que puede resumirse en las siguientes líneas: un tiempo nuevo se avecina, y se manifiesta en dos hechos: la casi totalidad de los viejos grupos anclados en la prensa tenderán a desaparecer, fragmentarse o integrarse en nuevas plataformas de medios, y el resto de grupos, cuyos "oficios de base" no provienen del mundo periodístico, se enfrentarán a una fuerte competencia marcada por la lucha de contenidos junto con las empresas de telefonía, los grandes players de internet $\mathrm{y}$ algunas exitosas plataformas de video on demand (VOD).

La metodología parte de dos fundamentos. Por un lado, la raíz conceptual que aportan la economía política de la comunicación y la economía industrial. Respecto de la primera, como refería Mosco (1996), proporciona un marco teórico integrado que se centra especialmente en la propiedad y la concentración de los medios de comunicación. En otras palabras, según Garnham (2011), muestra también un interés especial por la estructura de la industria de los media, su regulación y las políticas que aplican los diferentes gobiernos, focalizándose también en los procesos de concentración. En este sentido, subraya Sierra (2013), se necesitan trabajos de investigación que observen la vinculación entre Estado, mercado, corporaciones multimedia, procesos de concentración industrial, políticas públicas y desarrollo económico. Y la segunda analiza la estructura y el comportamiento de los mercados y de las empresas, y sirve para estudiar las decisiones estratégicas que, a lo largo de este periodo de cuarenta años, han desarrollado los grupos de comunicación, así como las inversiones y desinversiones llevadas a cabo en este periodo, al mismo tiempo que sus fuentes de financiación y sus procesos de endeudamiento.

Por otro lado, el método de análisis diacrónico (con series que, con cierta flexibilidad y entendiéndose como paradigmas y marcadoras de tendencias, comienzan en 2007) explica — y describe- los fenómenos com- 
parándolos con otros que se han presentado. En este método, se perciben los fenómenos sociales como una fase en un proceso dinámico (Sahagún, 2014).

Para afrontar el trabajo, se recurre también a una amplia revisión documental de la literatura académica de referencia y, sobre todo, se analizan fuentes primarias como los planes generales de contabilidad (balances y memorias) de las empresas de medios españolas, así como los informes de la Comisión Nacional del Mercado de Valores (CNMV), la Comisión Nacional de los Mercados y la Competencia (CNMC) y el Registro Mercantil para recabar datos sobre las empresas no cotizadas y que guardan un cierto grado de opacidad.

Asimismo, se recaban datos sobre informes, cifras de difusión, audiencia y contratación publicitaria, como OJD-Introl, comScore, Infoadex, AMI (antigua AEDE), Digimedios, Barlovento Comunicación/Kantar Media, y de instituciones como APM y AEDE, que facilitan una información no integrada de los diferentes sectores de actividad y se centran en buena parte en los fenómenos periodísticos.

\section{El desarrollo de los media en España: cuadro de "perdedores y ganadores"}

Al igual que en otros países europeos, los procesos de privatización de medios de comunicación y las consiguientes estrategias de integración vertical y horizontal, comenzadas a finales de la década de los ochenta y continuadas con profundas modificaciones en la década de los noventa, llevaron a que las empresas mediáticas sufriesen profundas transformaciones, inéditas hasta entonces, y propiciadas, en opinión de Albarrán (2010), por una conjunción de factores decisivos, como las reformas regulatorias, la puesta en marcha de los procesos de digitalización y los procesos globalizadores.

Parece claro, como indicaba Jin (2011, p. 167), que "la promesa de las economías de escala, la consecución de sinergias y el convencimiento de los potenciales beneficios de una producción y distribución coordinadas de productos culturales propició que muchos grupos abrazasen la estrategia de la convergencia mediática”. 
Del mismo modo, y al igual que muchas otras industrias culturales, los media siempre han sido terreno abonado para la "oligopolización" (Noam, 2009), si bien los niveles de concentración que se dan en España resultan superiores a los de la mayor parte de países de la UE (Pérez, 2010), sobre todo si consideramos el enorme poder del duopolio televisivo formado por las dos grandes plataformas Atresmedia y Mediaset España, que ya controlan casi el $90 \%$ de la publicidad en televisión, más del $50 \%$ de la inversión publicitaria en medios convencionales y el $57 \%$ de la audiencia total, como ya había previsto García (2013). Una concentración que encuentra igualmente correspondencia en la radio española, donde Unión Radio - que tiene como socio mayoritario al Grupo Prisa- dispone de alrededor de un $40 \%$ de la audiencia total, mientras que los tres mayores grupos radiofónicos privados cuentan con más de dos tercios de la contratación publicitaria.

Por otra parte, y salvo las acertadas inversiones de Prisa Radio en América Latina, España tampoco dispone de conglomerados que hayan tenido éxito en su internacionalización, como así ha sucedido con numerosas empresas del selectivo IBEX 35. Pero, sin duda, uno de los factores - ya apuntado - que más ha contribuido al declive de buena parte de los grandes grupos de comunicación españoles han sido los malhadados efectos de los procesos de integración vertical $-\mathrm{y}$ en menor medida horizontal - emprendidos por la búsqueda de un tamaño óptimo para competir en el mercado nacional e internacional, así como su voluntad de constituirse en grupos multimedia, y así obtener mayores ventajas estratégicas (Stephan, 2005). O dicho en otros términos, para soportar estos procesos tan complejos "se requieren poderosos recursos de capital, junto con algunas dosis de paciencia, y la voluntad decidida de afrontar pérdidas recurrentes durante un buen número de años" (Sylvie et al., 2007, p. 99), algo impensable en empresas tan escasamente capitalizadas como los media españoles.

El resultado inmediato fue un enorme endeudamiento de la mayor parte de grupos (a excepción de Telecinco, propiedad de Mediaset Italia), cuyo ejemplo más ilustrativo fueron los EUR 5400 millones de deuda que llegó a alcanzar el Grupo Prisa en 2008, y que, a la postre, acabarían - junto con otras erróneas estrategias - por socavar el enorme poder desplega- 
do hasta entonces por el mayor conglomerado mediático español. Huelga decir que el elevado endeudamiento fue, en casi todos los casos, la consecuencia del fracaso de poner en marcha exitosos proyectos audiovisuales.

Así, todos aquellos grupos que en su día perdieron el control de alguna televisión generalista (Grupo Zeta y Godó), o no fueron capaces de poner en marcha un gran canal televisivo (Vocento, Unidad Editorial y Prensa Española), o fracasaron en el desarrollo de una televisión de pago (Prisa) quedaron fuera de la competición mediática (figura 1) y permanecen, ahora, aferrados a un sector en crisis como el de la prensa que, entre 2007 y 2017, ha experimentado un descenso del $70 \%$ en la publicidad contratada (tabla 1) y una merma en sus ingresos, superior en euros constantes al $50 \%$, por no mencionar los profundos déficits en sus transformaciones digitales, la pérdida de calidad periodística y de su centralidad como diarios de referencia.

Figura 1. Comparación de los ingresos (operacionales) y el Ebitda de los principales grupos de prensa en España (en millones de euros) entre 2015 y 2016 (salida de la crisis).

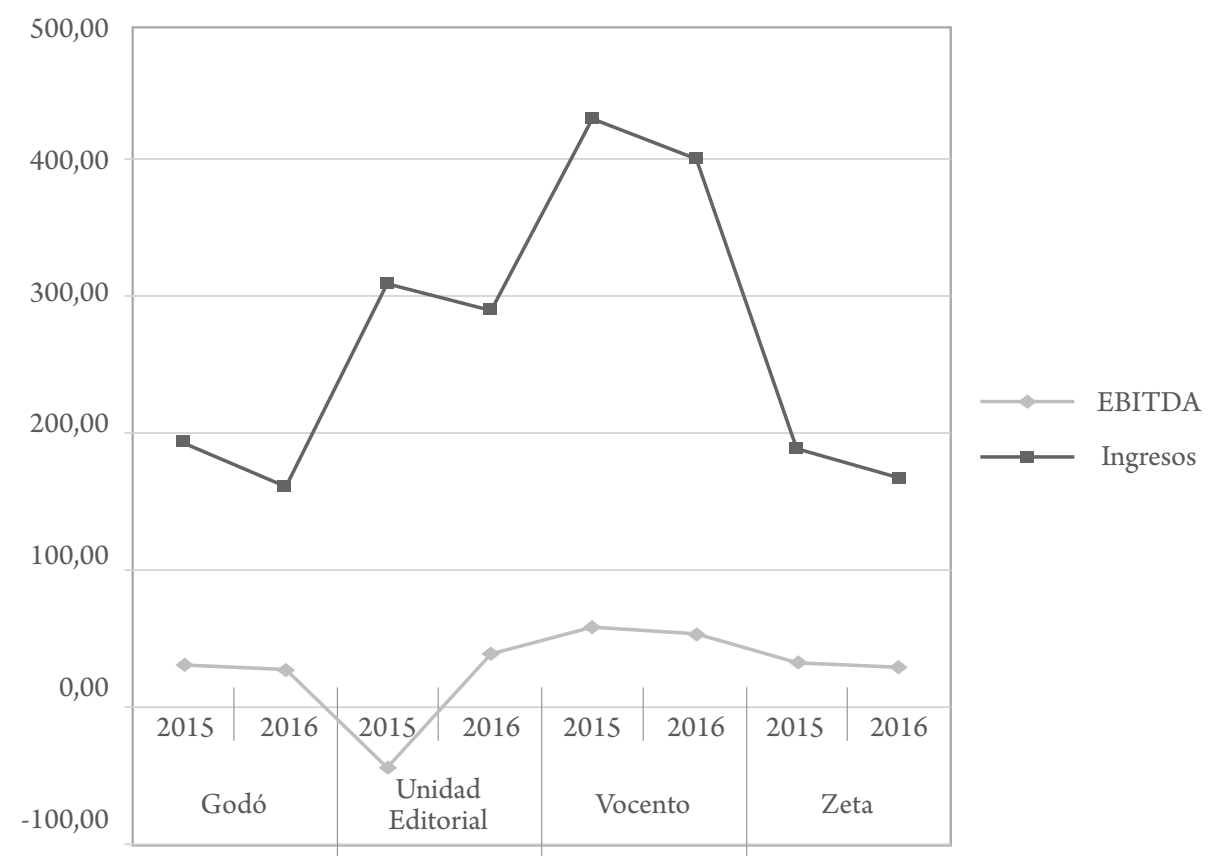




\begin{tabular}{|c|c|c|c|c|c|}
\hline \multirow{2}{*}{ Denominación social } & \multirow{2}{*}{ Leyenda } & \multicolumn{2}{|c|}{ Ingresos } & \multicolumn{3}{c|}{ Ebitda } \\
\cline { 3 - 6 } & & $\mathbf{2 0 1 5}$ & $\mathbf{2 0 1 6}$ & $\mathbf{2 0 1 5}$ & $\mathbf{2 0 1 6}$ \\
\hline Grupo Godó & Godó & 186,17 & 151,71 & 17,45 & 13,02 \\
\hline Unidad Editorial & Unidad Editorial & 305,17 & 285,09 & $-61,43$ & 25,27 \\
\hline Vocento & Vocento & 431,36 & 400,74 & 44,83 & 39,47 \\
\hline Grupo Zeta & Zeta & 178,58 & 159,38 & 18,37 & 14,89 \\
\hline
\end{tabular}

Fuente: elaboración propia según Bureau van Dijk (2018).

Tabla 1. Evolución de la inversión publicitaria en medios convencionales entre 2007 y 2017 (en millones de euros)

\begin{tabular}{|c|c|c|c|c|c|c|c|c|c|c|c|c|}
\hline $\begin{array}{l}\text { Años y } \\
\text { medios }\end{array}$ & 2007 & 2008 & 2009 & 2010 & 2011 & 2012 & 2013 & 2014 & 2015 & 2016 & 2017 & $\begin{array}{c}\text { Var. \% } \\
(07-17)\end{array}$ \\
\hline Diarios & 1894,40 & 1507,90 & 1174,10 & 1124,40 & 967,00 & 766,30 & 662,90 & 658,30 & 658,90 & 617,40 & 567,40 & $-70,05$ \\
\hline Dominicales & 133,50 & 103,90 & 68,90 & 72,20 & 67,10 & 52,00 & 38,70 & 37,70 & 37,80 & 33,80 & 31,00 & $-76,78$ \\
\hline Revistas & 721,80 & 617,30 & 401,90 & 397,80 & 381,12 & 313,70 & 253,90 & 254,20 & 255,20 & 252,20 & 240,10 & $-66,74$ \\
\hline Radio & 678,10 & 641,90 & 537,30 & 548,50 & 524,90 & 453,50 & 403,60 & 420,20 & 454,40 & 458,00 & 465,80 & $-31,31$ \\
\hline Televisión & 3468,60 & 3082,40 & 2237,80 & 2471,90 & 2237,20 & 1815,30 & 1703,40 & 1890,40 & 2011,30 & 2121,90 & 2143,30 & $-38,21$ \\
\hline Otros & 606,40 & 539,30 & 416,80 & 445,20 & 420,60 & 348,80 & 302,20 & 317,60 & 349,30 & 343,70 & 360,20 & $-40,60$ \\
\hline
\end{tabular}

Fuente: elaboración propia según Infoadex (2018).

Como detallaban Compaine \& Gomery (2000), a finales de la década de los ochenta, la situación de la industria de la prensa no era especialmente buena, aunque los resultados económicos arrojaban cifras positivas. Una paradoja que se produjo también en España, porque, aunque las cifras de difusión de la prensa indicaban claramente que desde 1994 hasta 1999 (en los Estados Unidos a partir de 1987) todos los grandes diarios de referencia españoles (a excepción de El Mundo) mostraban cifras declinantes, aumentaban, sin embargo, los ingresos de estos medios, impulsados por la bonanza de la economía. Y si bien la industria de los diarios de pago en España era una de las más importantes de Europa hasta la llegada de la crisis económica en el bienio 2007-2008, la conjunción entre las ventas de ejemplares, el éxito arrollador de algunas promociones de pago y la contención de los gastos de explotación generaron un marco aparentemente estable, que, a la postre, retrasó la necesaria llegada de la reconversión digital (García, 2016a). 
En otro orden de cosas, los grupos de comunicación surgidos tras los excesos de los años de bonanza (años de financiarización y de endeudamiento excesivo) y las consiguientes correcciones de los años de la crisis han dejado una gran cantidad de damnificados, con unos grupos más ligeros de activos (para satisfacer sus deudas bancarias) y una crisis tan enorme que (como demuestra el tabla de la inversión publicitaria entre 2007 y 2017) ha llevado a que la prensa española haya disminuido su inversión publicitaria de EUR 1894 millones en 2007 a solo EUR 567 millones en 2017, tres veces menos (figura 2).

\section{Figura 2. Ingresos de los principales grupos de prensa en España (en millones de euros) entre 2015 y 2016 (salida de la crisis).}

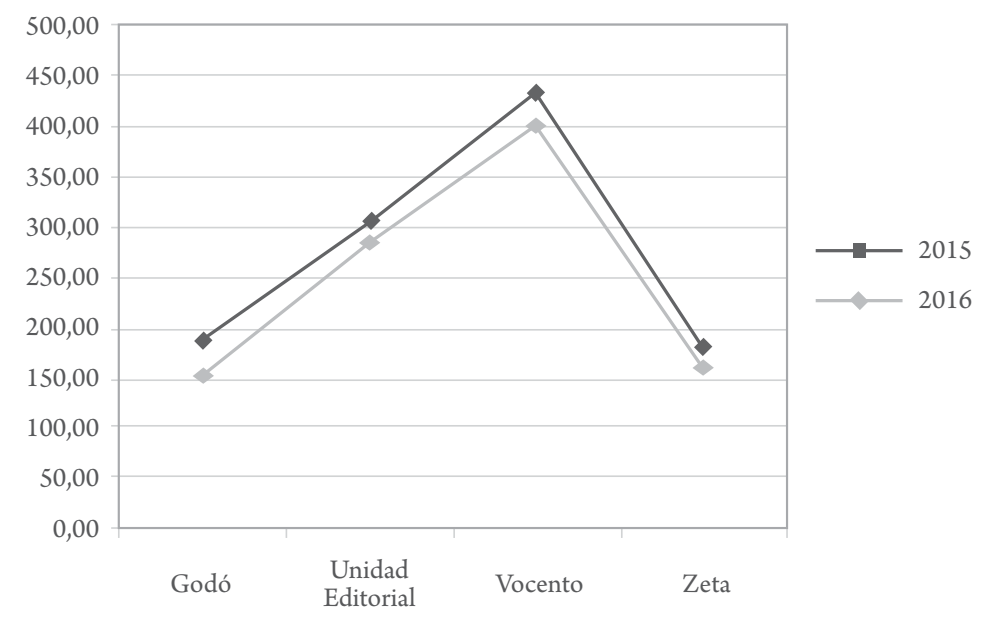

Fuente: elaboración propia según Bureau van Dijk (2018).

En las figuras 1 y 2, así como en las tablas 1 y 2, pueden apreciarse perfectamente los resultados de estas estrategias, la salida de la crisis económica, al igual que la enorme caída de ingresos y la escasa generación de Ebitda o cash flow operativo, que, según Vogel (2004), es el mejor indicador de eficiencia de las industrias culturales.

A las pérdidas experimentadas en el sector de la prensa se le unió el fracaso de los proyectos radiofónicos y televisivos de estas empresas. De este modo, tanto Unidad Editorial como Vocento decidieron, tras el fiasco de sus inversiones en radio y $\mathrm{TV}$, en el primer caso, y en el segundo, tras 
su fracaso radiofónico y televisivo, arrendar sus canales de televisión y sus postes de radio. La consecuencia inmediata fue el abandono de sus procesos de integración vertical y la reconcentración consiguiente en sus actividades de prensa (García et al., 2016).

Ahora bien, los resultados de los grupos concentrados mayoritariamente en el sector de la prensa contrastan fuertemente con los de las grandes cadenas televisivas. Así, Telecinco ha repartido, desde que en la década de los noventa comenzase a ganar dinero hasta hoy, unos EUR $2000 \mathrm{mi}-$ llones en dividendos, y en los peores años de la crisis, obtuvo unos beneficios de EUR 1438 millones.

Por su parte, el resto de los principales grupos presentes en el sector mediático, y durante el periodo 2008-2016, han visto cómo sus ingresos de explotación se han reducido en un $25,93 \%$. La excepción de este grupo la representa Mediapro, que en el periodo 2012-2016 incrementó sus ingresos de explotación en un 17,07\%.

\section{Tabla 2. Principales magnitudes económicas de los grupos de comunicación españoles en millones de euros (2008-2016)}

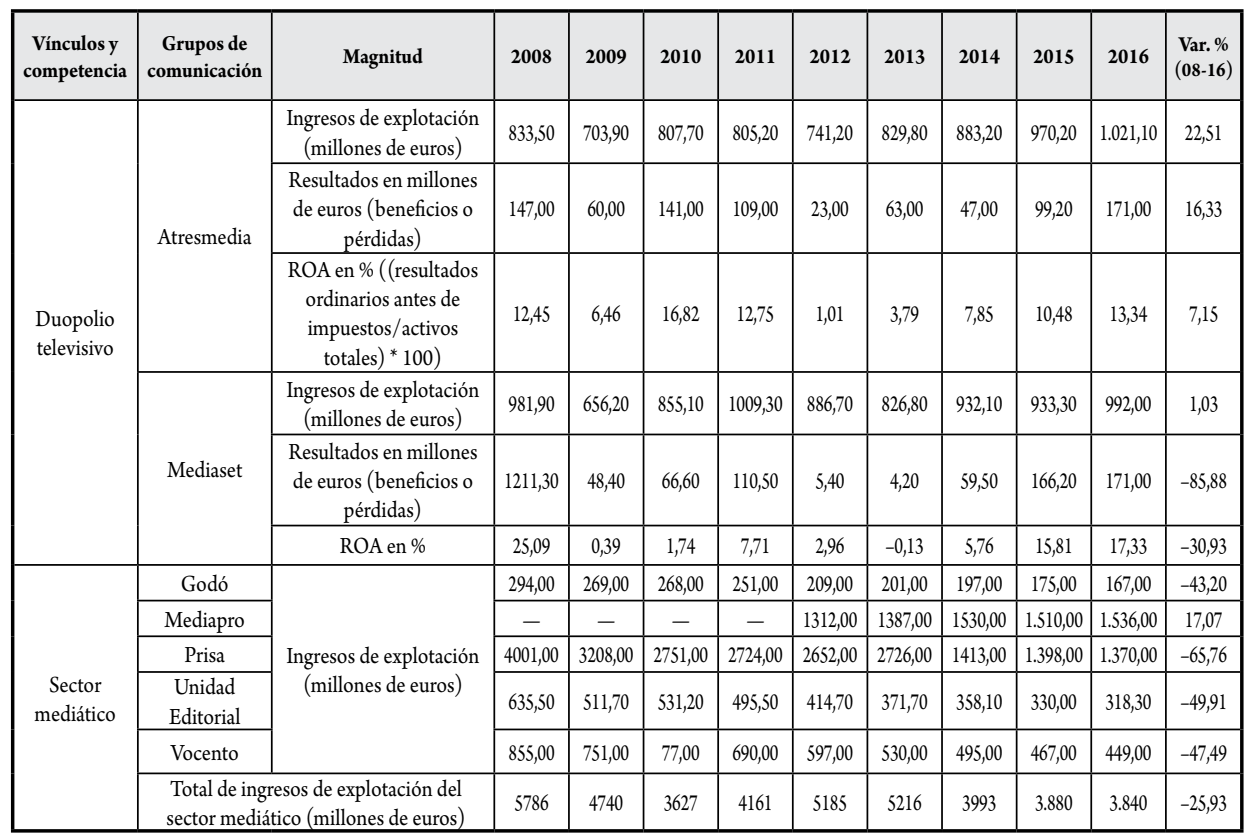

Fuente: elaboración propia según cuentas anuales de los grupos y Bureau van Dijk (2018). 


\section{Estudio de casos}

Con el estudio de casos de los principales grupos multimedia, pretendemos arrojar una mayor precisión sobre la evolución vivida en estos años.

\section{El duopolio televisivo: Mediaset España y Atresmedia}

En una primera etapa (finales de la década de los ochenta y principios de la década de los noventa), la televisión privada tuvo elevadas pérdidas hasta consolidar una oferta atractiva para anunciantes y audiencia (Bustamante, 2006).

La Ley 10/1988, de 3 de mayo de 1988 permitió la concesión de tres licencias: dos cadenas en abierto (Telecinco y Antena 3) y un canal de pago por satélite (Digital+). Antena 3 (hoy Atresmedia) fue dominada, en primera instancia, por el grupo catalán Godó y después pasó a manos de otro grupo de origen catalán (Zeta), hasta que, sorpresivamente, Telefónica compró su participación accionarial, que fue vendida a comienzos del siglo XXI a otro grupo catalán (Planeta). Pero el fracaso en este proyecto televisivo dejó desde entonces fuera de competición a Godó y Zeta. A su vez, Prisa se vio obligada a vender la participación del $56 \%$ que le quedaba a Telefónica en 2014, tras haber desinvertido previamente en Cuatro (adquirida por Telecinco) y cerrar Localia y CNN+.

Con la creación del duopolio (absorciones de Cuatro y La Sexta), las principales cadenas privadas fueron apoderándose de buena parte de las audiencias, los contenidos y los ingresos generados por la contratación publicitaria, además de desplazar a las productoras independientes de cine y de modificar las condiciones de contratación de las mayores productoras de contenidos de ficción, es decir, se modificó toda la cadena de valor audiovisual (García et al., 2014) (figura 3).

Las razones habría que buscarlas en un hecho evidente: tras el aumento de canales privados (24) llevado a cabo por el primer gobierno de Rodríguez Zapatero (2004-2008), la llegada de la crisis económica propició una profunda transformación de la televisión en España. El segundo Gobierno de Zapatero (2008-2011) contribuyó, precisamente, a que se pro- 
dujesen las absorciones (Ley 7/2009, de 3 de julio de 2009 y Ley $7 / 2010$, de 31 de marzo de 2009) de Cuatro por Telecinco y de La Sexta por Antena 3, que acabaron por consolidar dos grandes plataformas televisivas, con 14 canales y un claro duopolio televisivo que puso a buen recaudo a ambas empresas durante los peores años de la crisis económica.

Figura 3. Evolución de las audiencias en porcentaje de Atresmedia y Mediaset (2010-2017).

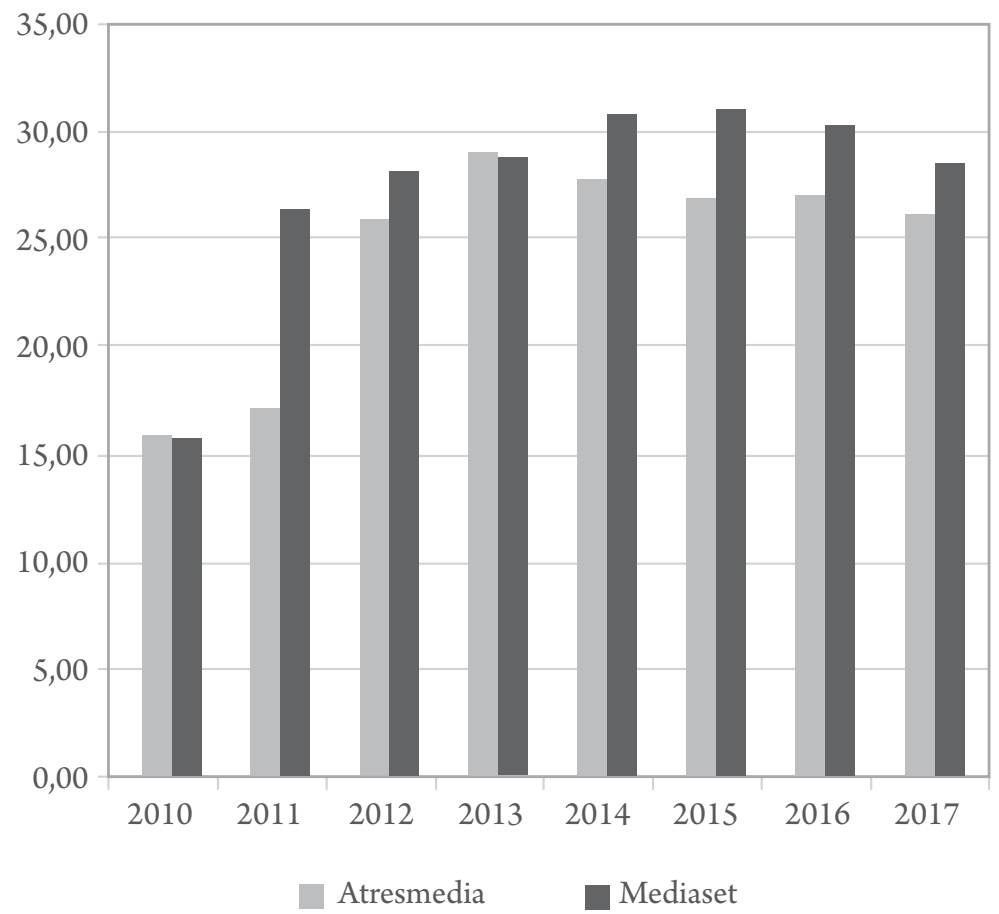

Fuente: Kantar Media (2018).

Así, y mientras que buena parte de los grupos multimedia españoles atravesaban una delicada situación financiera, Mediaset España y Atresmedia se situaban en una posición envidiable en relación con sus competidores que ganaron entre 2007 y 2017 EUR 2300 millones en beneficios. Un hecho que no hubiera sido posible sin la retirada de publicidad de RTVE tras su nueva y restrictiva ley de financiación (Ley 8/2009, de 28 de agosto de 2009) y su abandono de algunos derechos de retransmisión de grandes eventos deportivos. 
Actualmente, ambas cadenas han vuelto a superar la barrera de los EUR 1000 millones de ingresos netos, las cuales se beneficiaron del gran despegue del mercado televisivo en España que ha logrado alcanzar, en su conjunto, una facturación de EUR 64000 millones entre 2000 y 2015.

\section{El declive del Grupo Prisa}

El Grupo Prisa ha vuelto prácticamente a sus orígenes: un diario de referencia (El País), además de Cinco Días, As y su participación en The Huffington Post, la Editorial Santillana y la Cadena SER. La reducción de su deuda a tan solo EUR 818 millones en el segundo trimestre del ejercicio 2018 (figura 4) permite ahora una mayor viabilidad del grupo, aunque para ello haya tenido que despojarse en el camino de toda su división audiovisual; el $25 \%$ de Santillana y otros activos menores, además de una sustancial reducción de plantilla.

Figura 4. Evolución de la deuda del Grupo Prisa (2003-2018) en millones de euros.

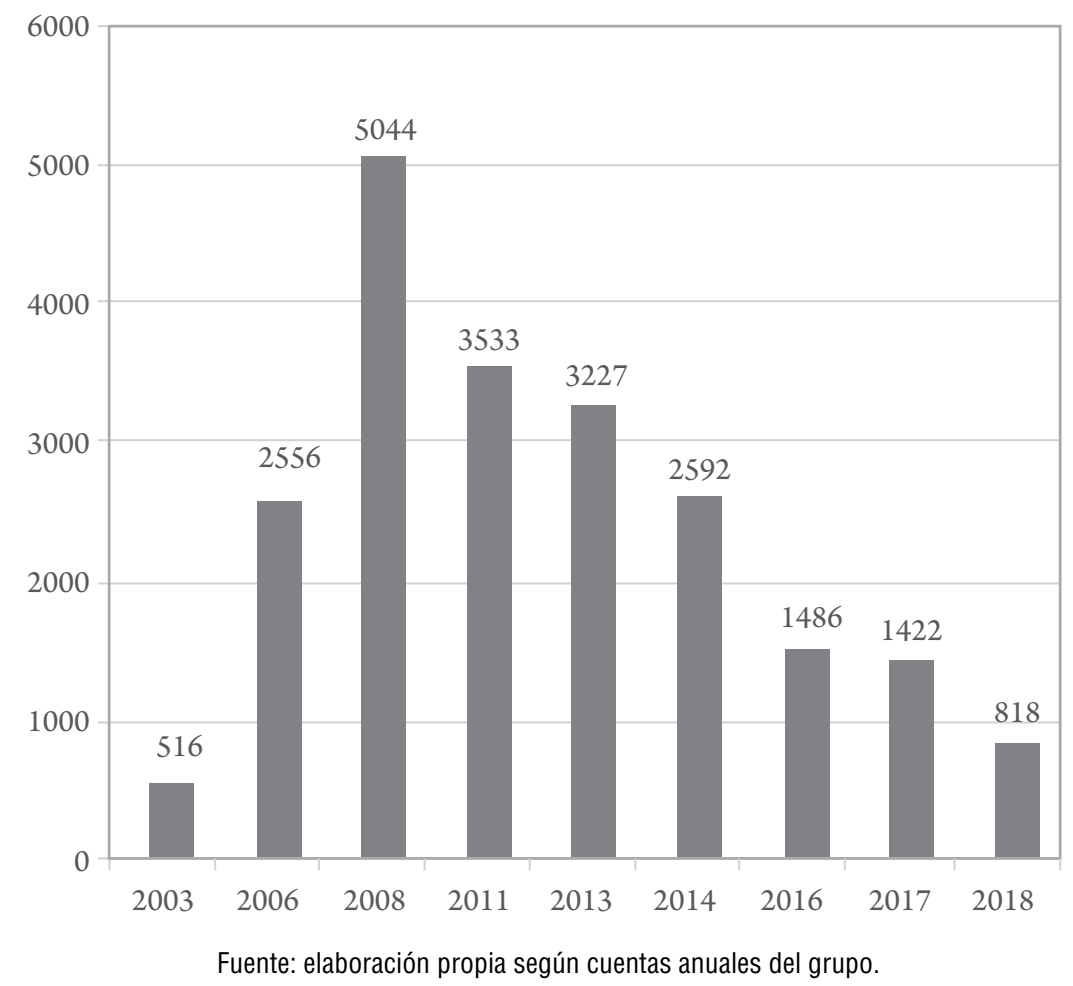


El futuro del Grupo Prisa — una vez que su presidente, Juan Luis Cebrián, ha dejado las tareas ejecutivas - está más despejado desde el punto de vista económico, pero solo Santillana genera el Ebitda suficiente como para mantener a la compañía y parece inviable recuperar, incluso, una mínima parte de su división audiovisual. Al igual que en su día le sucedió a Canal+ France (antes de su compra por Vivendi), pagó caros los errores estratégicos en su división audiovisual y en su política de expansión en otros mercados.

Del mismo modo, la compañía ha sufrido las complejidades que siempre comporta una televisión de pago: un gasto excesivo en derechos de retransmisiones deportivas y la firma de contratos en exclusiva con las majors (output deals), que supusieron unos desembolsos de tal calibre que, como demuestra la tabla 3, llevaron a que la compañía perdiera, entre 2010 y 2017 , EUR 3987 millones (según las memorias del Grupo Prisa de 2011 a 2018), debido también a las fuertes minusvalías con las que vendió su $56 \%$ de Canal+ a Telefónica; un precedente mundial que solo puede encontrarse en Canadá (Winseck, 2010).

Por otra parte, la empresa experimentó una reducción significativa de su tamaño empresarial al ir desprendiéndose de empresas y participaciones en otras compañías. Así, de unos ingresos de explotación de EUR 4001 millones en 2008 pasó a tan solo EUR 1170 millones en el ejercicio 2017, casi cuatro veces menos, con la consiguiente reducción de su Ebitda de EUR 780 a EUR 207 millones.

\section{Tabla 3. Resultados anuales del Grupo Prisa entre 2007 y 2017} en millones de euros

\begin{tabular}{|c|c|c|c|c|c|c|c|c|c|c|c|}
\hline Magnitudes & $\mathbf{2 0 0 7}$ & $\mathbf{2 0 0 8}$ & $\mathbf{2 0 0 9}$ & $\mathbf{2 0 1 0}$ & $\mathbf{2 0 1 1}$ & $\mathbf{2 0 1 2}$ & $\mathbf{2 0 1 3}$ & $\mathbf{2 0 1 4}$ & $\mathbf{2 0 1 5}$ & $\mathbf{2 0 1 6}$ & $\mathbf{2 0 1 7}$ \\
\hline $\begin{array}{c}\text { Ingresos de } \\
\text { explotación }\end{array}$ & 3696 & 4001 & 3208 & 2751 & 2724 & 2652 & 2726 & 1413 & 1398 & 1370 & 1170 \\
\hline Ebitda & 780 & 948 & 623 & 502 & 437 & 477 & 296 & 268 & 289 & 282 & 207 \\
\hline Resultado neto & 289 & 83 & 50 & -72 & -451 & -255 & -801 & -2237 & 5 & -68 & -103 \\
\hline
\end{tabular}

Fuente: elaboración propia según cuentas anuales del grupo. 
El Grupo Prisa ha dejado, por tanto, de liderar — lastrada por las desinversiones - el sistema de medios español y también muchos desarrollos e innovaciones tecnológicos en el campo audiovisual. Una pérdida de "centralidad”, culminada en 2014, que carece de marcha atrás (figura 5).

\section{Figura 5. Estructura del capital social del Grupo Prisa (febrero de 2018).}

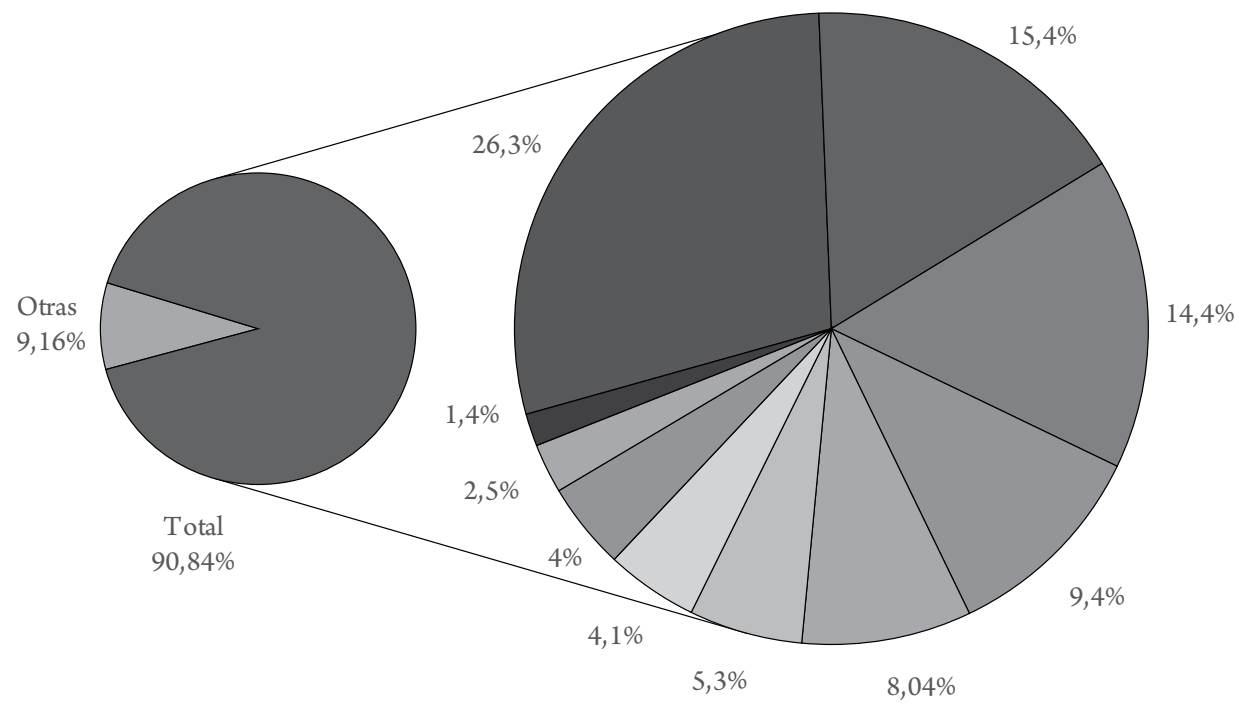

\begin{tabular}{|c|c|c|}
\hline Leyenda & Nombre o denominación social del accionista & $\begin{array}{c}\text { \% sobre el total de } \\
\text { derechos de voto }\end{array}$ \\
\hline 1 & Amber Capital UK LLP (Joseph Oughourlian) & 26,30 \\
\hline 2 & Rucandio S. A. (familia Polanco) & 15,40 \\
\hline 3 & HSBC & 14,40 \\
\hline 4 & Telefónica S. A. & 9,40 \\
\hline 5 & Roberto Alcántara & 5,04 \\
\hline 6 & Adar Capital & 4,10 \\
\hline 7 & Banco Santander & 4,00 \\
\hline 8 & Carlos Fernández & 2,50 \\
\hline 9 & Nicolás Berggruen & 1,40 \\
\hline 10 & CaixaBank & 50 \\
\hline
\end{tabular}

Fuente: elaboración propia según CNMV (febrero de 2018) y Grupo Prisa (febrero de 2018). 
La otra consecuencia importante es que ha pasado de tener a los Polanco, familia fundadora del grupo, como socio mayoritario a poseer solo el 15,4\% del capital (CNMV, 2018), mientras que fondos de inversión y bancos, que se vieron obligados a convertir deuda financiera en acciones de la compañía, ya controlan el $54 \%$ (aparte del 9,4\% de Telefónica), un proceso claro de financiarización (Jivkova y Pérez, 2015), que no solo compromete la independencia del grupo, sino también su futuro.

\section{Los grupos emergentes (Planeta y Mediapro) y el regreso de Telefónica}

Los recambios inmediatos al liderato alcanzado por el Grupo Prisa desde finales de la década de los ochenta han sido rápidamente cubiertos por Planeta, Telefónica y Mediapro.

La Editorial Planeta, en su alianza con la Editorial DeAgostini, controla el $37 \%$ de Atresmedia, además de la cadena de emisoras Onda Cero y el diario La Razón. Ha logrado consolidar una plataforma televisiva muy competitiva; la primera por facturación, aunque Mediaset la adelante en beneficios. Las únicas preocupaciones sobre su futuro estriban en la deuda que la matriz ha contraído tras la compra de la segunda editorial de libros franceses, Editis, adquirida en 2008 por unos EUR 1000 millones, de los cuales solo pagó en efectivo EUR 50 millones (figura 6).

El diario digital El Español apuntaba (4 de julio de 2017) que la deuda a largo plazo del grupo rozaba, a finales de 2015, los EUR 1500 millones; cien veces más que su beneficio neto. Hoy día, su deuda asciende a EUR 1190 millones a largo plazo y a EUR 164 millones a corto plazo, y se han visto obligados a vender en mayo de 2018 su sede de Barcelona al Banco Sabadell como pago de la deuda contraída con esta entidad financiera.

Una parte muy importante de este pasivo procede de la unificación de su deuda histórica en un solo crédito sindicado de más de EUR 1000 millones en 2010, un préstamo de EUR 270 millones para Atresmedia y la refinanciación de la deuda con Editis por valor de EUR 465 millones. Complementariamente, una serie de inversiones lideradas por Planeta en otros sectores de actividad — como el de la banca — han conducido a esta situación. 


\section{Figura 6. Facturación de los principales grupos mediáticos en España en 2017 en millones de euros.}

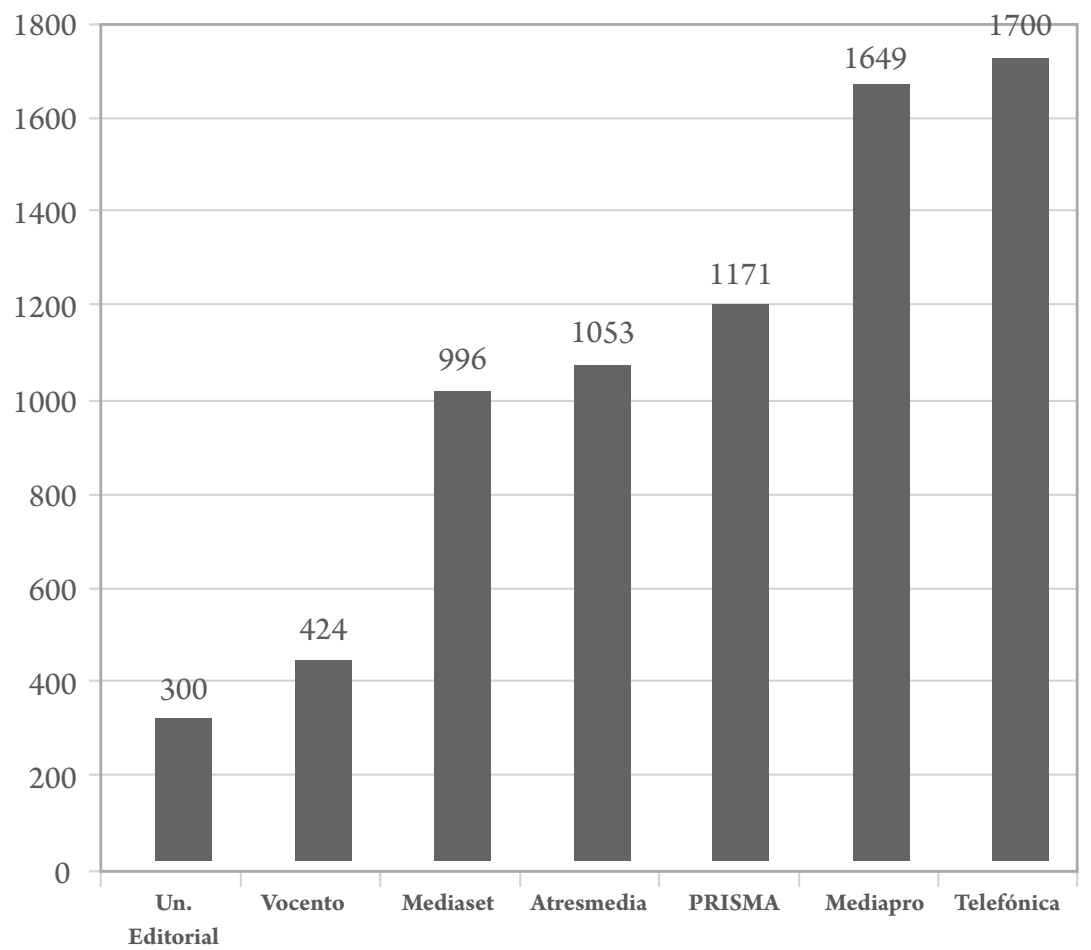

Nota: la facturación de Telefónica se ha calculado en atenció a sus ingresos en España durante 2017, de los que, según la compañía, el 13,5\% representan la parte audiovisual.

Fuente: elaboración propia según datos de las compañías.

En cuanto a Mediapro, empresa que en muy pocos años ya lidera - con el permiso de Telefónica - el ranking español de grupos de comunicación, tomando como referencia sus ingresos de explotación, es también el grupo de más reciente creación (Barcelona, 1994). Primer carrier independiente de España, opera en diferentes ámbitos de actividad audiovisual, aunque cuenta con una fuerte especialización $-\mathrm{y}$ hasta excesiva concentración y riesgo - en gestión de derechos deportivos y retransmisiones de diferentes deportes, pero muy especialmente del fútbol. Tiene actualmente los derechos de la Champions League para España, y se ha adjudicado los derechos de la Ligue 1 francesa desde la temporada 2020-2021 hasta la 2023-2024 (figura 7). 
Figura 7. Ingresos netos de los principales grupos mediáticos españoles durante 2015 a 2017 en millones de euros.

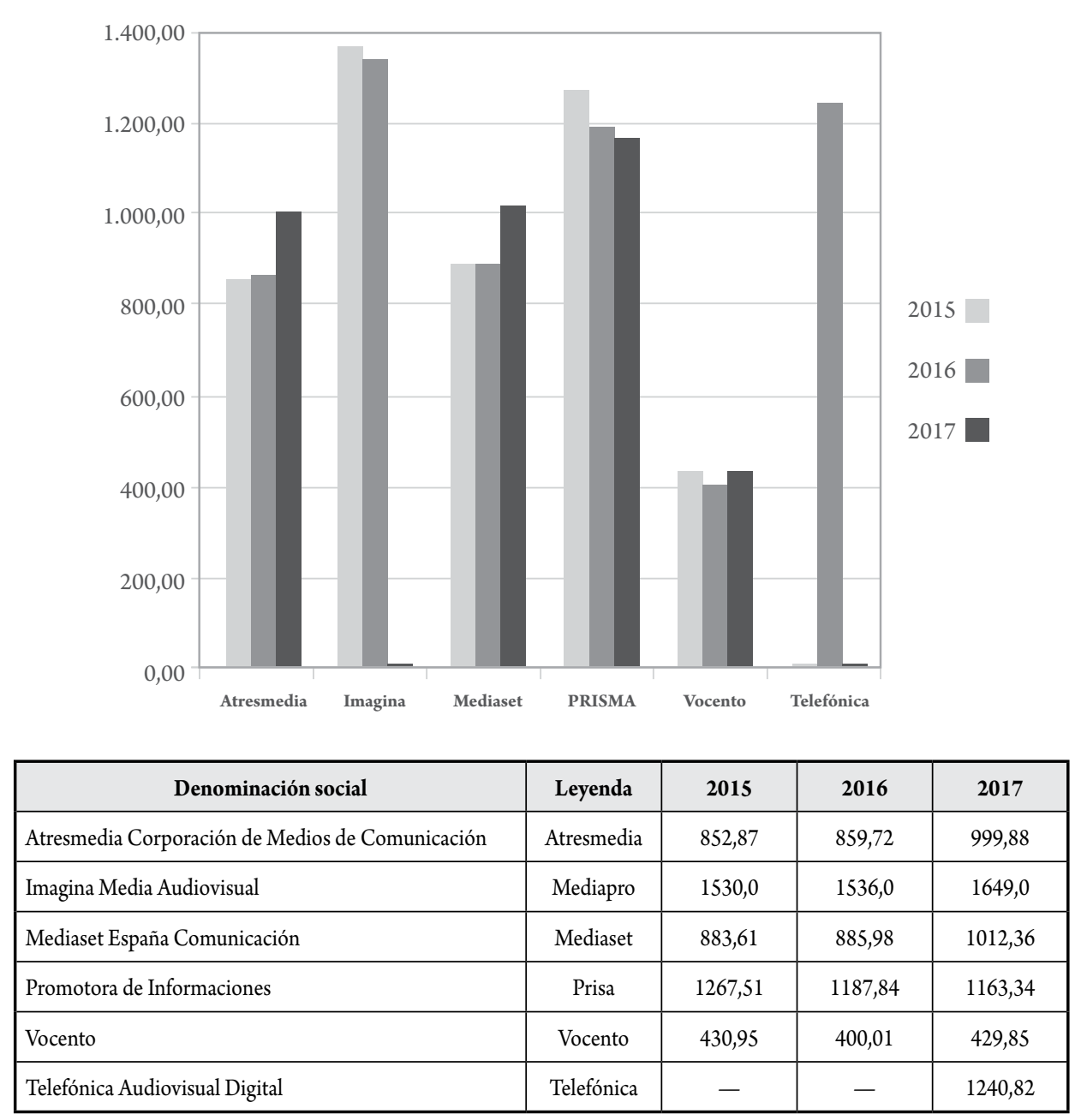

Fuente: elaboración propia según Bureau van Dijk (2018).

Su facturación en 2017 fue la mayor de su historia con EUR 1649 millones y un Ebitda de EUR 189 millones. A comienzos de 2018, Orient Hontai Capital, el primer grupo chino de capital privado, ha tomado el control de Mediapro y se ha adjudicado el 53,5 \% de la compañía por EUR 1016 millones tras comprar las acciones de Televisa, Torreal y Mediavideo. El resto de los socios son la multinacional WPP $(22,5 \%)$ y dos de los socios fundadores del grupo: Jaume Roures (12\%) y Tatxo Benet (12\%). 
El punto débil de la compañía es, por tanto, la gran dependencia de los derechos del fútbol y la escasa diversificación en otros mercados. Como es sabido, la gestión de estos derechos ha sido la causa de la quiebra de grupos como el alemán Kirch. El sistema prevé solo dos modos de comercialización: la cesión de su explotación a terceros mediante la inclusión de un canal propio (Bein Sports) en otra plataforma o la comercialización directa con una plataforma propia. Pero, en el primero de los supuestos, caso de España, los principales operadores de telefonía opusieron una fuerte resistencia a la adquisición de esta "reventa" de derechos. De ahí que Telefónica se haya hecho (junio de 2018) con el principal paquete de derechos de la liga de fútbol española y Mediapro se replantee su diversificación como empresa de creación de contenidos de ficción.

En cuanto a Telefónica, siempre ha tenido, al menos desde 1994 (Fundesco, 2006), una presencia activa en medios de comunicación, con inversiones puntuales en Endemol, Recoletos, Vía Digital, Antena 3 y Onda Cero, pero, tras el nombramiento de César Alierta como presidente de la compañía en 2002, se reconcentró más en el core de su negocio, por lo que se desprendió de la mayor parte de sus participaciones de medios en España. Sin embargo, en 2014, y apuntando una tendencia clave en la comunicación mundial, la empresa ha devenido en buena parte una $T V$ company, que intenta producir sus propios contenidos para alimentar a sus canales de pago.

Es en ese bienio 2013-2014, como ya apuntara la consultora Deloitte (2014), y como anticipaba López (2011), cuando empiezan a converger tres industrias sobre la televisión: audiovisual, telecomunicaciones e informática. Y, como más recientemente ha subrayado Campos (2016, p. 150), "el tradicional sistema audiovisual europeo del siglo XX se está fragmentando y diversificando con la entrada de nuevos competidores convergentes procedentes del sector de las telecomunicaciones y de los infomediarios de internet (OTT, por sus siglas en inglés) que están cambiando las reglas de juego de la competencia comercial".

La oferta comercial de Telefónica es ya una oferta convergente (Movistar Fusión), desde finales de 2012, y supone el 38 \% de la facturación de la 
compañía en España (Telefónica, 2018), cuando hace tan solo cuatro años representaba el $22 \%$. Yla estrategia se está extendiendo — no exenta de dificultades - a los países de América Latina donde está presente la compañía.

Las incógnitas de futuro siguen siendo si Telefónica será capaz de replicar, al menos para España y Latinoamérica, la estrategia seguida por la AT\&T norteamericana, su capacidad para producir contenido propio que compita en igualdad de condiciones con otros grupos de comunicación y operadores VOD como Netflix y HBO, y su disposición a alcanzar alianzas estratégicas con empresas de internet, productores locales y grandes operadores de VOD (como ya ha conseguido en España con Netflix).

\section{Discusión, resultados y conclusiones}

La primera década del siglo XXI ha visto alumbrar, por tanto, algunas novedades muy interesantes en los media españoles, muy en línea con las transformaciones que se están produciendo en la comunicación mundial, y que podemos observar también en otros continentes (Reig y Labio, 2017).

Las grandes televisiones generalistas tienen un liderazgo claro en la televisión en abierto y han vuelto a la senda de la facturación de EUR 1000 millones anuales, aunque con las incógnitas inherentes al modelo broadcasting en todo el mundo. Esa gran máquina de repartir dividendos (alrededor de EUR 2000 millones desde creación, según la propia compañía) que ha sido Telecinco (ahora Mediaset España) difícilmente —al igual que Atresmedia— revivirá sus mejores años.

Los datos de contratación publicitaria de Infoadex (2015-2017) no dejan lugar a dudas: la inversión publicitaria en televisión se ha estancado: EUR 2011 millones en 2015, EUR 2122 en 2016 y EUR 2140 millones en 2017. Es muy improbable, por tanto, que vuelva a alcanzar los EUR 3469 millones de 2007, y solo el hecho de que se encuentren en una situación duopolística les permite seguir disfrutando de beneficios recurrentes. Pero, además, como en otros lugares del planeta, el mayor crecimiento de las opciones de VOD, fundamentalmente Netflix (con EUR 1,4 millones abonados en 2018, según el Panel de Hogares de la CNMC), se acompaña de 
crecimientos más moderados e, incluso, con tendencia al estancamiento, para las plataformas de las empresas de telecomunicaciones (Movistar+).

Ahora bien, los grupos de comunicación que han emergido de la crisis (2007-2016) poco tienen que ver - sobre todo en el aspecto financiero- con aquellos grupos que habíamos conocido a comienzos del siglo $\mathrm{XX}$, cuando eran frecuentes valoraciones generosas de sus activos que la realidad bursátil puso después en su sitio. No vemos, por consiguiente ( $\mathrm{y}$ corroborando nuestra hipótesis), ninguna viabilidad futura para grupos que han perdido el tren de la digitalización y de las redes sociales, con públicos muy envejecidos y sin un modelo de negocio claro. Y puesto que la mayor parte de sus unidades de negocio arrojan desde el comienzo de la crisis hasta hoy resultados negativos, solo puede preverse la irrupción de un triple escenario:

- Una mayor concentración entre grupos anclados en prensa, como la muy comentada de Vocento y Unidad Editorial, que, a la postre, no serviría para resolver los problemas de ambos grupos.

- Una venta ordenada de cada uno de estos grupos: un panorama poco viable, por cuanto habría que adquirir activos y pasivos, es decir, la deuda que acarrean estos grupos, y aun no siendo así, muchas de sus unidades de negocio carecen de valor futuro.

- Un "troceamiento" de estos vendiendo sus unidades más rentables o aparentemente más rentables a diferentes compradores. Una opción que vemos más viable. $\mathrm{O}$ dicho de otra manera, siempre puede haber compradores para adquirir el mayor diario económico, el mayor diario deportivo o el mayor diario de referencia.

Otras fórmulas irán seguramente desde la simple desaparición de muchos medios y de sus matrices, su integración en plataformas lideradas por empresas de internet o el desarrollo de novedosas alianzas estratégicas, como las que están llevando a cabo empresas de telefonía e internet.

También se ha producido la pérdida de algunos "intangibles", necesarios, en muchos casos, para un país que es el quinto mercado de la UE por número de consumidores. Si el Reino Unido, Francia, Alemania e Ita- 
lia cuentan con sus "campeones nacionales" (Sky, Canal+ France, Bertelsmann y Mediaset), España ya ha dejado de contar con el Grupo Prisa, que, tras perder toda su división audiovisual, ha quedado reducida a los niveles de finales de la década de los ochenta.

Todo ello demuestra el cumplimiento de los objetivos y corrobora la hipótesis. Y, además, predispone, como se apuntaba desde el inicio, a lanzar una visión de futuro clara, aunque no muy halagüeña. En este sentido, si bien la AMI (2017) indica que a partir de 2014 se ha iniciado una tendencia ascendente, todavía no se ha producido la recuperación de los volúmenes de ingresos anteriores a la crisis. A un mercado que hasta hace poco tiempo, y salvo el importante concurso de la alemana Bertelsmanzn y las italianas Mediaset y DeAgostini no estaba muy penetrado por la inversión extranjera en medios de comunicación, se le han sumado las profundas transformaciones en la comunicación mundial. Con las tomas de posición de los grandes players de internet (Apple, Facebook, Amazon y Google), junto con las de las grandes empresas de telecomunicaciones (AT\&T y Telefónica entre ellas), y la reordenación del mapa de los grandes grupos mundiales de comunicación y la emergencia de las plataformas de VOD Directiva de servicios de comunicación audiovisual, que entrará en vigor en España en 2020 para contribuir, también, a la promoción del cine europeo, y a que las operadoras más importantes de servicios VOD reserven al menos un $20 \%$ de sus catálogos a la producción europea, puede abrirse un panorama de futuro más esperanzador, pero solo en el ámbito audiovisual. $\mathrm{Al}$ resto, le espera un futuro demasiado gris.

\section{Referencias}

Albarrán, A. B. (2010). The media economy. Routledge.

Álvarez, J. T. (1989). Historia de los medios de comunicación en España. Ariel. Asociación de Medios de Información. (2017). El Libro Blanco de la Información 2017. Autor.

Asociación de la Prensa de Madrid. (2010-2017). Informe anual de la profesión periodística. Autor. 
Atresmedia (2007-2018). Informes anuales y de responsabilidad corporativa. https://www.atresmediacorporacion.com/responsabilidad-corporativa/informes/informes-anuales-atresmedia_20170607593 7c9e70cf26391845efcf5.html

Barlovento Comunicación. (2005-2018). Análisis televisivo. https://www. barloventocomunicacion.es/audiencias-anuales/analisis-televisivo-2018/

Bureau van Dijk. (2018). Orbis [Fichero de datos].https://ucm.on.worldcat. org $/$ search?lang $=$ es \&clusterResults $=$ off \&stickyFacetsChecked $=0$ n\&queryString=orbis\#/oclc/956269887

Bustamante, E. (2006). Radio y televisión en España. Gedisa.

Campos Freire, F. (2016). El valor social de la televisión en abierto. En E. Gutiérrez Montes (Coord.), Televisión abierta: situación actual $y$ tendencias de futuro de la TDT. (pp. 147-168). Colegio Oficial de Ingenieros de Telecomunicaciones. https://www.academia. edu/33239790/Televisi\%C3\%B3n_Abierta_Situaci\%C3\%B3n Actual_y_tendencias_de_futuro_de_la_TDT

Comisión Nacional de los Mercados y la Competencia. (2018, mayo 25). Panel de hogares. https: / /www.cnmc.es/novedades/2018-05-25-panel-de-hogares-cnmc-368441

Comisión Nacional del Mercado de Valores. (2018). Promotora de Informaciones S. A. https://www.cnmv.es/Portal/HR/ResultadoBusquedaHR.aspx?nif=A28297059\&division $=1$

Compaine, B. M. \& Gomery, D. (2000). Who owns the media? Competition and concentration in the mass media industry. Routledge.

Deloitte. (2014). Tecnología, medios de comunicación y telecomunicaciones: predicciones 2014. https://www2.deloitte.com/content/dam/Deloitte/es/Documents/tecnologia-media-telecomunicaciones/Deloitte_ES_TMT_Predicciones-2014.pdf 
Díaz Nosty, B. (2001). Informe anual de la comunicación 2000-2001. Grupo Zeta.

Directiva 2010/13/UE del Parlamento Europeo y del Consejo, de 10 de marzo de 2010, sobre la coordinación de determinadas disposiciones legales, reglamentarias y administrativas de los Estados miembros relativas a la prestación de servicios de comunicación audiovisual (Directiva de servicios de comunicación audiovisual).

Directiva (UE) 2018/1808 del Parlamento Europeo y del Consejo de 14 de noviembre de 2018 por la que se modifica la Directiva 2010/13/ UE sobre la coordinación de determinadas disposiciones legales, reglamentarias y administrativas de los Estados miembros relativas a la prestación de servicios de comunicación audiovisual (Directiva de servicios de comunicación audiovisual), habida cuenta de la evolución de las realidades del mercado.

Fernández Alonso, I. y Santana Cruz, F. (2000). Estado y medios de comunicación en la España democrática. Alianza.

Fundación para el Desarrollo de la Función Social de las Comunicaciones. (1989-1996, 2006). Informes anuales de Fundesco. Autor.

García Santamaría, J. V. (2013). Televisión y concentración en España: el duopolio de Mediaset y Atresmedia. Palabra Clave, 16(2), 366397. https://doi.org/10.5294/pacla.2013.16.2.4

García Santamaría, J. V. (2016a). La crisis de la prensa escrita en España: algunas razones para su tardía transición digital. En J. V. García Santamaría y F. Pérez Bahón (Coords.), Los medios digitales españoles: procesos de cambio e innovación. (pp. 11-24). Cuadernos Artesanos de Comunicación. http://www.cuadernosartesanos. org/2016/cac104.pdf

García Santamaría, J. V. (2016b). Los grupos multimedia españoles: análisis yestrategias. UOC. 
García Santamaría, J. V., Pérez Serrano, M. J. y Alcolea Díaz, G. (2014). Las nuevas plataformas televisivas en España y su influencia en el mercado. Revista Latina de Comunicación Social, 69, 390-417. https:// doi.org/10.4185/RLCS-2014-1017

García Santamaría, J. V., Pérez Serrano, M.J.y Alcolea Díaz, G. (2016). Unidad Editorial como caso de estudio sobre las limitaciones de la integración horizontal en el sector de la prensa. Textual and Visual Media, 9, 133-154. https://textualvisualmedia.com/index.php/ txtvmedia/article/view/207

Garnham, N. (2011). The political economy of communication revisited. En J. Wasko, G. Murdock \& H. Sousa (Eds.), The handbook of political economy of communications. (pp. 41-61). Wiley Blackwell.

Hope, W. (2014). Global capitalism, temporality, and the political economy of communication. En J. Wasko, G. Murdick \& H. Sousa (Eds.), The handbook of political economy of communications. (pp.521-540). John Wiley \& Sons.

Infoadex. (2018). Estudio de inversión publicitaria en España 2017. Autor.

Jin, D. Y. (2011). Deconvergence and deconsolidation in the global media industries: The rise and fall of (some) media conglomerates. En D. Winseck \& D. Y. Jin (Eds.), The political economies of media: The transformation of the global media industries. (pp. 167-182). Bloomsbury.

Jivkova Semova, D. y Pérez Serrano, M. J. (2015). Formas alternativas de financiación en los grupos mediáticos españoles: fondos de inversión, hedge funds y sociedades capital riesgo. Ámbitos: Revista Internacional de Comunicación, 28, 1-13. https://idus.us.es/xmlui/ handle/11441/66531

Jones, D. E. (1996). Transformaciones en el sistema comunicativo español (1976-1996). Trípodos, 2, 169-190. 
Kantar Media. (2018). Anuario de audiencia TV2018. https://anuario.kantarmedia.es/

Kerlinger, F. N. y Lee, H. B. (2002). Investigación del comportamiento. McGraw-Hill.

Ley 11/1982, de 13 de abril, de supresión del organismo autónomo Medios de Comunicación Social del Estado.

Ley 10/1988, de 3 de mayo, de Televisión Privada.

Ley $7 / 2009$, de 3 de julio, de medidas urgentes en materia de telecomunicaciones. BOE núm. 161 (2009).

Ley 8/2009, de 28 de agosto, de financiación de la Corporación de Radio y Televisión Española. BOE núm. 210 (2009).

Ley 7/2010, de 31 de marzo, General de la Comunicación Audiovisual. BOE núm. 79 (2010).

López Villanueva, J. (2011). La reconfiguración de la cadena de valor. En J. M. Álvarez-Monzoncillo (Coord.), La televisión etiquetada: nuevas audiencias $y$ nuevos negocios. (pp.9-31). Ariel.

Martínez Nicolás, M. y Saperas Lapiedra, E. (2011). La investigación sobre comunicación en España (1988-2007): análisis de los artículos publicados en revistas científicas. Revista Latina de Comunicación Social, 66, 101-129. https://doi.org/10.4185/RLCS-66-2011926-101-129

Martínez Nicolás, M. y Saperas Lapiedra, E. (2016). Objetos de estudio y orientación metodológica de la reciente investigación sobre comunicación en España (2008-2014). Revista Latina de Comunicación Social, 71, 1365-1384. https://doi.org/10.4185/ RLCS-2016-1150es 
Mediaset España.(2007-2017).Información financiera: informes anuales. https:// www.mediaset.es/inversores/es/informacion-financiera.html

Mosco, V. (1996). The political economy of communication: Rethinking and renewal. Sage.

Noam, E. M. (2009). Media ownership and concentration in America. Oxford University Press.

Pérez Serrano, M. J. (2010). La concentración de medios en España: análisis de casos relevantes en radio, prensa y televisión. Universidad Complutense de Madrid.

Prisa. (2000-2017). Cuentas anuales auditadas e informe de gestión. https:// www.prisa.com/es/datos/cuentas-anuales

Reig, R. y Labio, A. (Coords.) (2017). El laberinto mundial de la información: estructura mediática y poder. Anthropos.

Sahagún, F. (2014, noviembre 12). Metodología. http://felipesahagun.es/ metodologia/

Sierra Caballero, F. (2013). Hacia una epistemología del sur: comunicología latina y agenda de investigación. En M. M. Krohling Kunsch (Orgs.), La comunicación en Iberoamérica: políticas científicas y tecnológicas, posgrado y difusión del conocimiento. (pp. 25-46). Centro Internacional de Estudios Superiores de Comunicación para América Latina.

Stephan, M. (2005). Diversification strategy of global media conglomerates: A comment. Journal of Media Economics, 18(2), 85-103. https:// doi.org/10.1207/s15327736me1802_1

Sylvie, G., LeBlanc, J. W., Hollifield, C. A., Lacy, S. \& Broadrick, A. S. (2007). Media management: A casebook approach. Routledge Communication Series. 
Telefónica (2018). Informe anual. https://www.telefonica.com/es/web/ shareholders-investors/informacion_financiera_y_registros_oficiales/informe-anual

Vocento. (2007-2017). Memorias anuales. http://www.vocento.com/

Vogel, H. L. (2004). La industria de la cultura y el ocio: un análisis económico. Fundación Autor.

Winseck, D. (2010). Financialization and the "crisis of the media": The rise and fall of (some) media conglomerates in Canada. Canadian Journal of Communication, 35(3), 365-393. https://doi.org/10.22230/ cjc.2010v35n3a2392 